\title{
Around Voltammetry: from Colouring Matters to Beer
}

\author{
A.A. Barros * \\ REQUIMTE, Departamento de Química da Faculdade de Ciências da Universidade do Porto, \\ Rua do Campo Alegre, 687, 4169-007 PORTO, Portugal
}

Received 14 November 2005

\section{In honour of Prof. João Cabral}

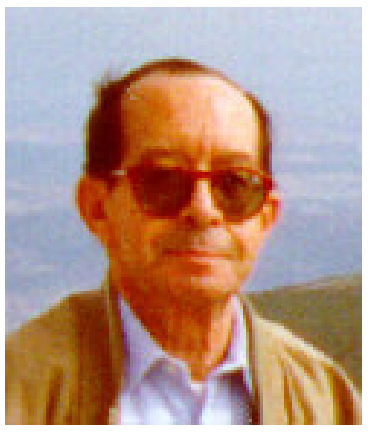

\begin{abstract}
This paper is based on the plenary lecture that I was invited to present in the VIII Encontro Ibérico de Electroquímica and XIII Encontro da Sociedade Portuguesa de Electroquímica, a meeting which was "a tribute to the late Prof. João Cabral". The best way I found to honour his memory was to present the highlights of an investigation of 25 years in voltammetry, which would never happen without the enthusiasm and the guidance of Prof. João Cabral.

After a first publication, in 1986, on the adsorptive stripping voltammetry of synthetic colouring matters, our investigation was soon directed towards the new analytical possibilities opened by the appearance of new voltammetric instrumentation capable of very fast potential scans. The instrumental elimination of oxygen interference obtained in the fast adsorptive stripping of some species reversibly reducible on the hanging mercury drop electrode (HMDE) was a first achievement, immediately followed by the development of a HMDE flow detector for the determination of those species. This detector is being applied in the flow determination of several compounds, with the determination of diacetyl deserving a special reference. In fact the determination of this compound it is very important for the brewing industry and it was possible to develop an equipment capable of its determination in flow: diacetyl is extracted from beer by pervaporation, then derivatized with orto-phenytlenediamine and finally determined by HMDE adsorptive stripping voltammetry.
\end{abstract}

Keywords: Prof. João Cabral, adsorptive stripping voltammetry, HMDE, oxygen elimination, flow detection, diacetyl, beer.

\footnotetext{
* Corresponding author. E-mail address: ajbarros@fc.up.pt.
} 


\section{Introduction}

The supervision and the guidance of Prof. João Cabral were no doubt of utmost importance for the evolution of my professional career, in general, and for the definition of my investigation options, in particular. In fact, in 1981, after 8 years of assistant, when I finally decided to choose an university career, this was only possible due to the offer of Prof. João Cabral to supervise my Ph. D. work. The investigation that he proposed to me was the re-analysis of the subject of his own Ph. D. work, finished 30 years before (1951): Polarographic Analysis of Azoic Dyes. This was my first contact with voltammetric analysis, a subject that became the main area of all my investigation.

When Prof. João Cabral got retired, in 1991, he begun, step by step, to share with me the guidance of Linha de Investigação $N^{0} 3$ do Centro de Investigação em Química da Universidade do Porto, a situation that only ended in 2003, with his death.

The following presentation describes the investigation in which I was involved in the last 25 years. I hope that the examples presented can help to show that, contrarily to what is being claimed, Analytical Chemistry is far from being a disappearing area. With those examples, all in the area of voltammetry, I also hope to prove the potentialities of a technique that has experienced a lot of difficulties in obtaining a wide acceptance.

\section{Adsorptive stripping voltammetry of synthetic colouring matters (1986)}

As part of my Ph. D. work, started in 1981, I visited the U. K. twice (1983 and $1985)$ to do some laboratory training. This was performed at the Loughborough University of Technology, under the supervision of Dr. Arnold Fogg, a scientist working in the area of the voltammetric analysis of colouring matters, precisely the area of my Ph. D. work. The main investigation performed during this period was on the possibility of determination of dyes using an emergent technique at the moment, adsorptive stripping voltammetry. The investigation was successful, leading to the publication of the first scientific work on the analysis of dyes using the mentioned technique, curiously 30 years after the publication of an important work of Prof. João Cabral in the same field using polarography [1,2].

For instance, an interesting result referred on this publication of 1986 was the effect of the addition of the surfactant tetraphenylphosphonium chloride (TPPC) in the analysis of the dye azorubine. The addition of TPPC caused a drastic increase on the voltammetric peak of the dye (Fig. 1), contrarily to the expected decrease due to the presence of a surfactant. As it will be mentioned later, only in 1999 we were able to obtain an explanation for this odd behaviour, when exploiting the new capabilities of voltammetric analysis, made possible by the new instrumentation of voltammetry launched in the beginning of the nineties.

\section{Polarographic analysis of colouring matters in corks (1991)}

The following episode, which was decisive in the future orientation of our investigation, would never have happened without the participation of Prof. 
Carlos Corrêa, the head of the section of Organic Chemistry of the Chemistry Department of the Faculty of Science, one of the more generous persons that I ever new. This professor, having been contacted by a Port Wine company to try to solve a problem related with the use of dyes to colour corks, immediately gave to them my contact saying that I was the expert on that subject. In fact, my Ph. D. thesis, entitled "Analytical control of synthetic organic dyes in drugs and cosmetics", published in 1986, contains a polarographic study of a lot of food dyes.

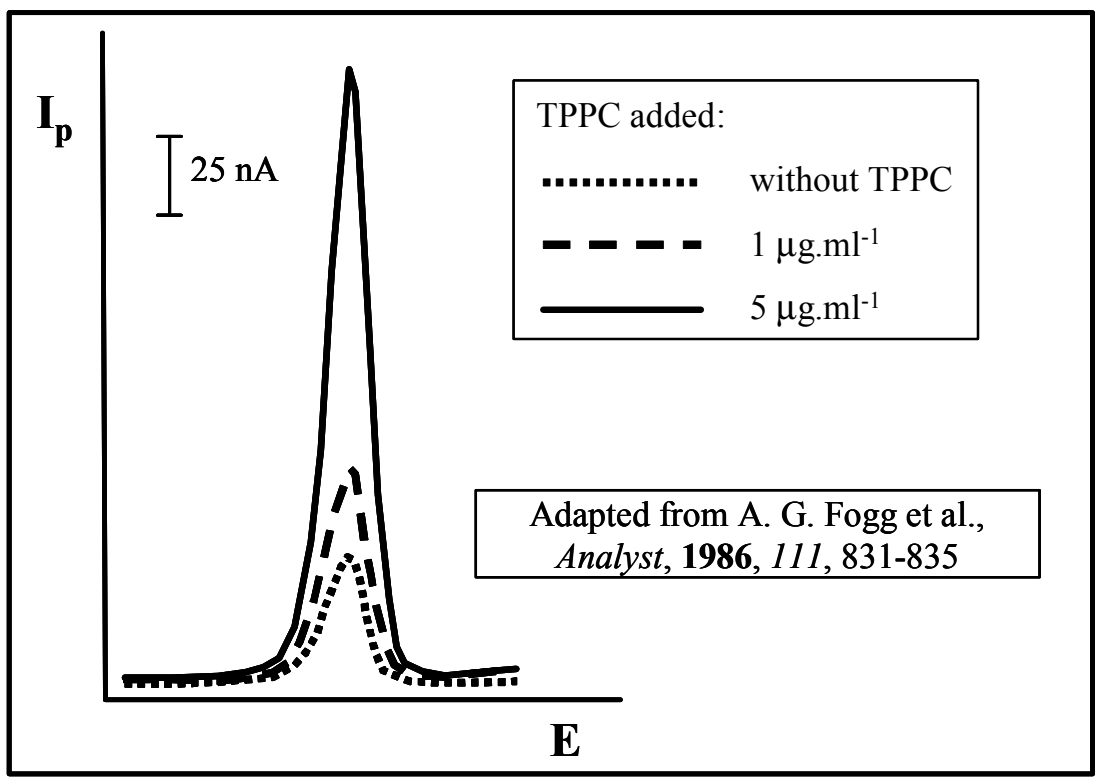

Figure 1. Effect of the addition of tetraphenilphosphonium chloride (TPPC) on the voltammetric analysis of the dye Azorubine $\left(9.2 \times 10^{-8} \mathrm{M}\right)$.

The problem of the Port Wine Company was quite interesting and the final result of our investigation on the subject is a comic example of the claimed "immiscibility" investigation/industry. The problem appeared when some millions of Port Wine bottles exported by the Portuguese wine company to France were refused by the French control authorities, claiming that the corks used to close the bottles were tainted with a dye not allowed to be used in foods. More precisely, they argued that the dye used was Orange II (not a food dye) instead of the food dye Sunset Yellow FCF. The difficulty is that it is not easy to distinguish between these dyes in corks, due to their chemical similarity. Anyway, we decided to compare the voltammetric behaviour of the two dyes to see if we could find any differences, but we were not able to distinguish them. In spite of this, we did not forget the problem, and Dr. José António Rodrigues (at the moment doing his Ph. D. work under my supervision) came to me some six months later showing polarographic conditions allowing the differentiation of the two dyes (Fig. 2). I contacted immediately the wine company and obtained a symptomatic answer: we are no more interested in that problem, because we 
were able to obtain an agreement with the French importers. Fortunately the work was not completely lost, as it was the basis of a scientific communication [3].

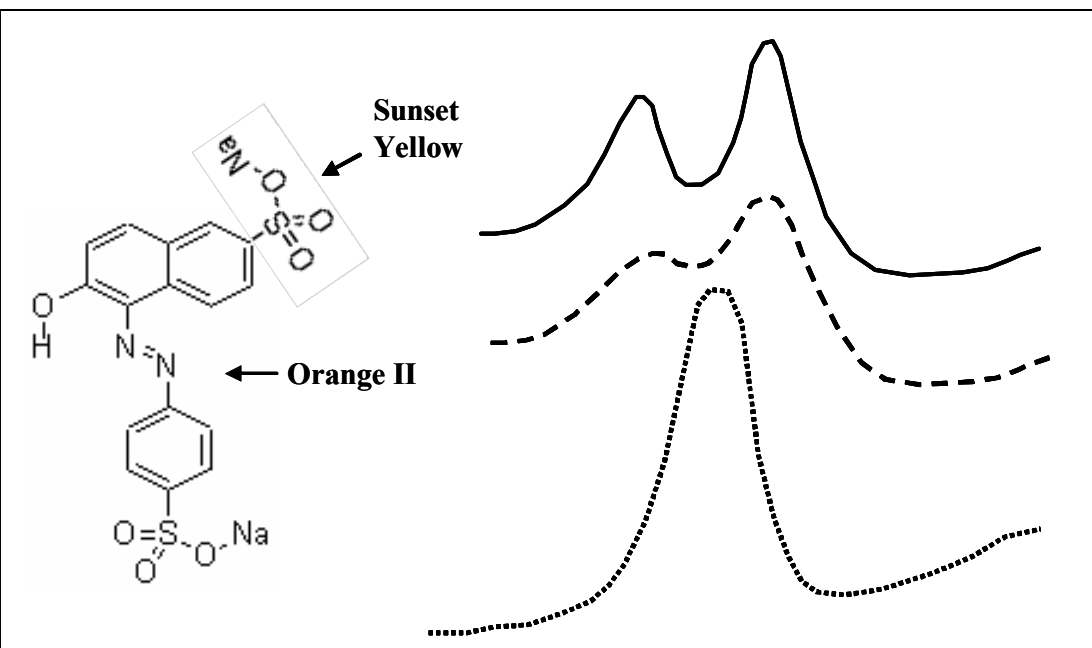

Figure 2. Effect of the addition of tetraphenylphosphonium chloride (TPPC) to a mixture of $1 \mathrm{ppm}$ of Sunset Yellow FCF and $1 \mathrm{ppm}$ of Orange II. TPPC added (ppm): $0 ;---100 ;-250$.

A. A. Barros et al., Electroanalysis, 1991, 3, 243

\section{Polarographic analysis of oxalate in corks (1993)}

In spite of the relative failure of the previous investigation, the wine company placed us a new challenge: would we be capable of developing a method for the determination of oxalic acid in corks? Oxalic acid is present on the surface of corks, because these, as a final step of their preparation, are immersed in a reductive bath of oxalic acid, by two reasons: to reduce the excess of oxidants previously used in the disinfection of the corks and to give them a more appealing looking by creating a deposit on their surface. This was the reason why I decided to propose the subject "voltammetric determination of oxalic acid" for the Ph. D. work of Dr. José António Rodrigues. At that moment we had no idea that this investigation would be the basis of some of the more important innovations that were introduced in our research some years later.

The objective was, then, to find out a possible way to determine oxalic acid voltammetrically. The direct determination is not adequate, but a methodology already used in other techniques was tried, with success. It is based on a reaction characteristic of alpha-dicarbonylic compounds (like oxalic acid) with ortophenylenediamine (OPDA) to form quinoxalines, which were found to be electrochemically active. The reactions involved in the determination are represented in Fig. 3. 


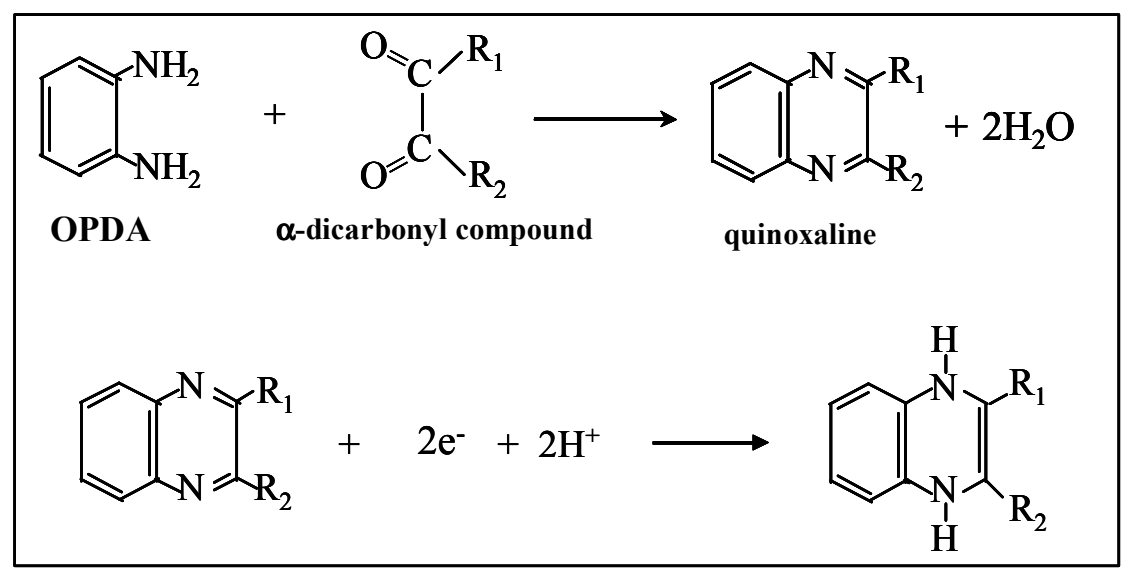

Figure 3. Derivatisation of alpha-dicarbonyl compounds with ortophenylelenediamine and voltammetric determination of the quinoxaline formed.

\section{Polarographic analysis of diacetyl in beer (1997)}

As a consequence of the methodology developed, the idea of determining oxalic acid was obviously enlarged to the determination of other alpha-dicarbonylic compounds. And it was at this moment that beer made its appearance. In fact, during a bibliographic research on the subject several references were found relating beer with diacetyl (Fig. $3-\mathrm{R}_{1}=\mathrm{R}_{2}=\mathrm{CH}_{3}$ ) and we decided to make a contact to the local brewery to know more about it. The reaction of Eng. Machado Cruz, quality director of the brewery at the moment (1994), was enthusiastic and we learnt that the determination of diacetyl is very important in brewing industry, by two reasons somewhat different: in one way, diacetyl is a compound formed during the production of beer which must be destroyed due to its undesirable organoleptic properties; in other way, its determination is used as a criterion for the end of the process of fermentation/maturation of beer (this process is ended when the level of diacetyl becomes less than a previously established value, generally 50 to $100 \mathrm{ppb}$ ).

One of the problems in the determination of diacetyl in beer is the interference of other alpha-dicarbonyl compounds also present (Table 1), especially methylglyoxal.

Table 1. Main $\alpha$-dicarbonyl compounds present in beer. Derivatisation with orto - phenylenediamine.

\begin{tabular}{|cc|c|c|}
\hline $\mathbf{R}_{\mathbf{1}}$ & $\mathbf{R}_{\mathbf{2}}$ & Compound & Derivatisation Product \\
\hline $\mathrm{H}$ & $\mathrm{H}$ & Glyoxal & Quinoxaline \\
\hline $\mathrm{H}$ & $\mathrm{CH}_{3}$ & Methylglyoxal & 2-Methylquinoxaline \\
\hline $\mathrm{CH}_{3}$ & $\mathrm{CH}_{3}$ & Diacetyl & 2,3-Dimethylquinoxaline \\
\hline $\mathrm{CH}_{3}$ & $\mathrm{CH}_{2} \mathrm{CH}_{3}$ & 2,3- Pentanodione & 2- Ethyl -3 - Methylquinoxaline \\
\hline
\end{tabular}


The separation of diacetyl can be obtained by distillation of beer (Fig. 4). Using simple distillation (Fig. 4 a) it is not possible to eliminate the interference of methylglyoxal. Nevertheless, this can be achieved using steam distillation (Fig. $4 \mathrm{~b}$ ): diacetyl is completely distilled in the first $20 \%$ of distillate (polarogram b1) without distillation of methylglyoxal, which only starts to appear in the following fractions of distillate (polarograms b2 and b3).

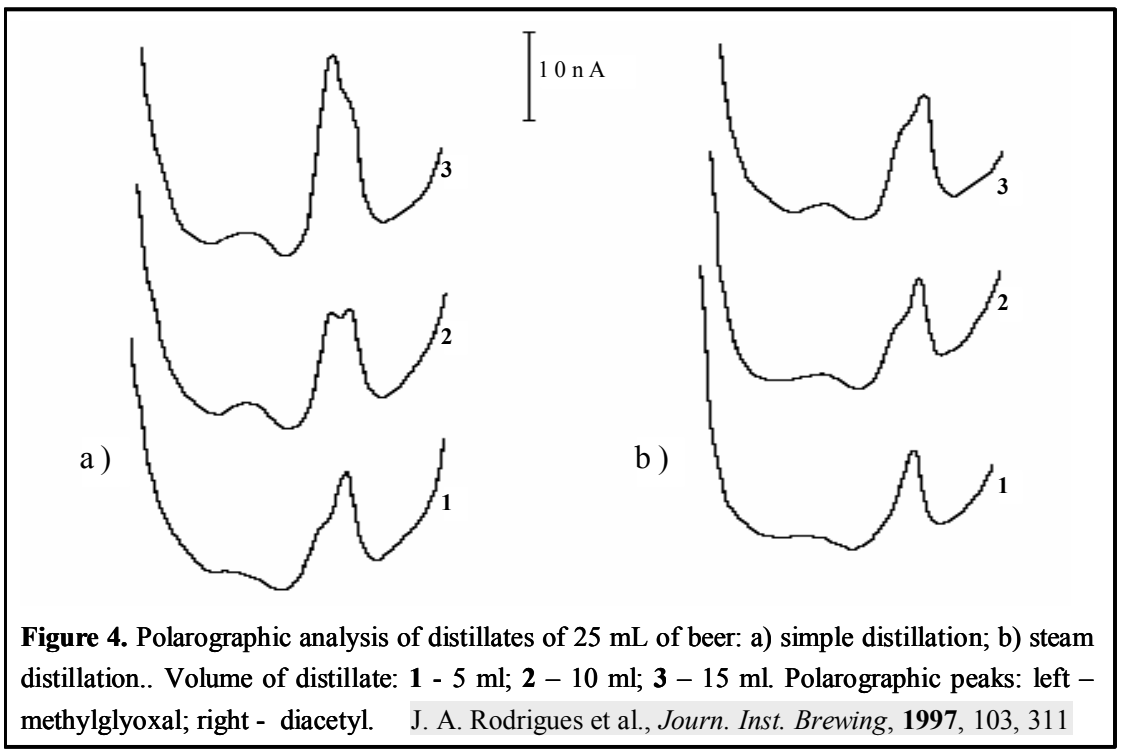

\section{Some innovative approaches of adsorptive stripping voltammetry (1999)}

The new generation of voltammetric instrumentation available since the beginning of the nineties open the way to a much easier exploitation of several aspects of voltammetry. One of the main advantages was the possibility of programming the potential functions. For instance, instead of having to use the fixed values of the old instruments, it was now possible to vary the value of the sampling time of the current intensity and to use very high potential frequencies associated with the technique of square wave.

Some of the new capabilities are being accepted quite slowly, although they are not very different from the old ones. For instance, due to the wide acceptance of differential pulse polarography (DPP) during several decades, its replacement by square wave voltammetry (SWV) is taking some time, although this last technique produces similar analytical results and is much faster. In Fig. 5 the similarity of the techniques is explained: SWV is a kind of DPP in which the time before the application of the pulse is suppressed (if we are not using a mercury drop electrode this time is not needed because there is no drop to be formed before the pulse application).

With the new potentialities of the last generation of voltammetric instrumentation it was possible to increase the analytical capabilities of adsorptive stripping voltammetry, as it is shown in the following examples. 

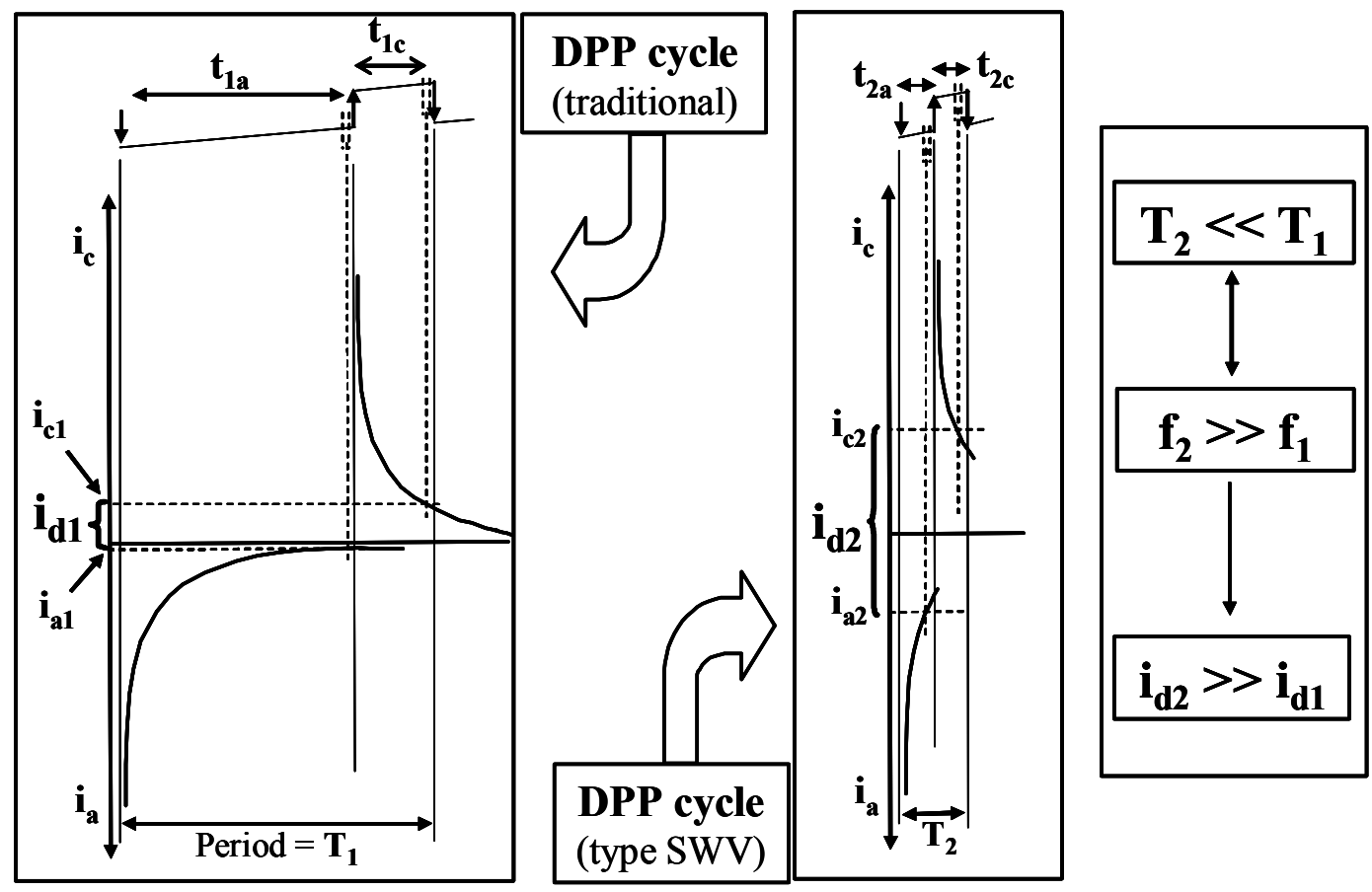

Figure 5. There is no substantial difference between SWV and DPP

\section{Understanding of an apparently odd result obtained in 1986}

As previously mentioned (Fig. 1, work published in 1986), the addition of the surfactant tetraphenylphosphonium chloride (TPPC) caused an unexpected increase on the voltammetric peak of the colouring matter Azorubine, a behaviour that could not be explained at the moment. This result could now be understood thanks to the additional capabilities of the new instruments of voltammetry, as it can be seen in Fig. 6. In fact, in the absence of TPPC the reduction reaction is so fast (curve A) that the voltammetric signal has already disappeared for the sampling times generally used in the old instrumentation. The addition of $5 \mathrm{ppm}$ of TPPC slows down the reaction (curve B), which can still be detected for higher pulse times (lower frequencies); as a result a signal increase is obtained in the presence of TPPC if a pulse time higher than $5 \mathrm{~ms}$ is used. Of course, if the frequency is high enough (lower sampling times) a "normal" situation is obtained, with the voltammetric signal decreasing with the addition of TPPC.

\section{Looking for "lost" peaks}

In a similar way it was possible to interpret a strange behaviour pointed out by Zanoni et al. (Anal. Chim. Acta, 315, 1995, 41) in the analysis of the anthraquinonic dye Procion Blue MX-R using adsorptive stripping voltammetry (Fig. 7).

At that moment, the authors could not explain why there was no voltammetric peak for the reduction of the anthraquinonic group. Using the capabilities of the new instrumentation it was possible to obtain the voltammograms represented in Fig. 8, which provide a simple understanding of the situation. 


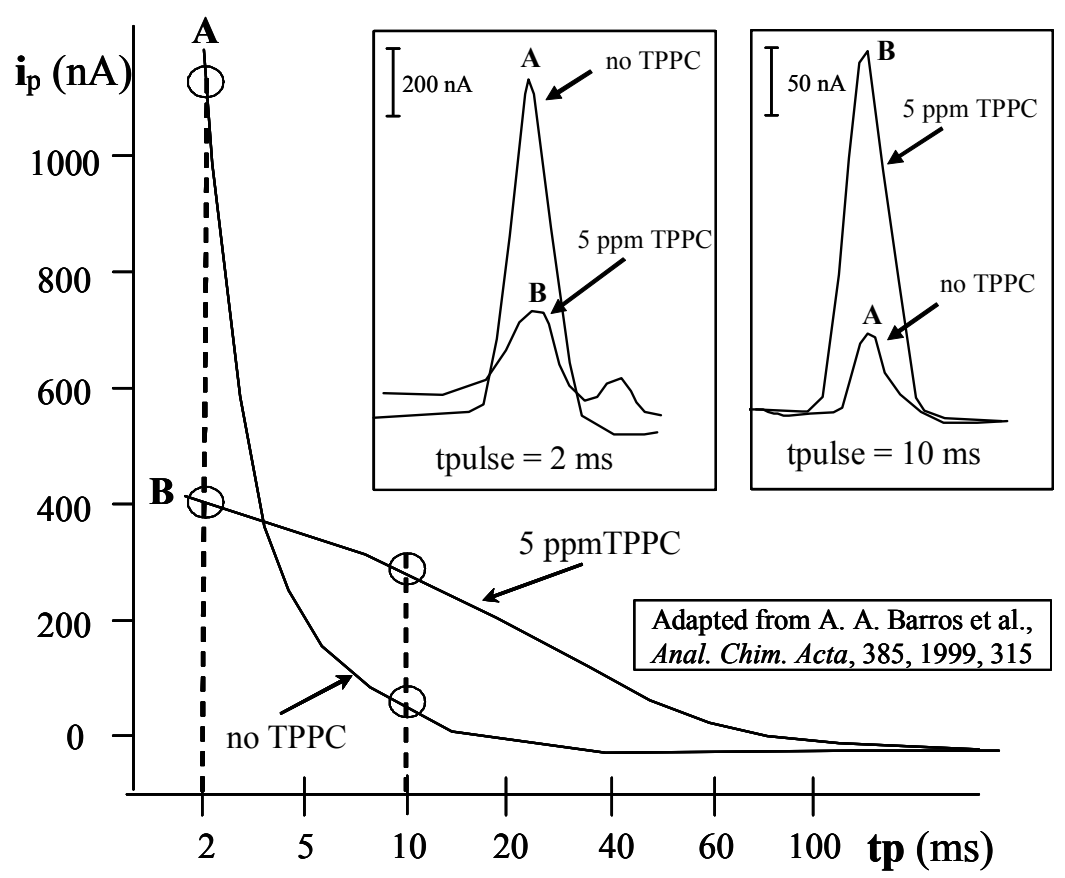

Figure 6. DPP analysis of $10^{-7} \mathrm{M}$ Azorubine (ammonia buffer, $\mathrm{pH}=9$ ). TPPC added (ppm): $\mathrm{A}-0 ; \mathrm{B}-5$. As the reaction slows down in the presence of TPPC, there is an increase of the voltammetric signal for pulse times higher than $5 \mathrm{~ms}$.

In fact, as the reduction reaction of the group anthraquinone is very fast, the equilibrium was already achieved for the frequency used by Zanoni (voltammogram a). Using a higher frequency it is possible to measure the current before the end of the reaction (voltammogram $b$ ). It is also possible to explain the different speed of growing of the anthraquinone peak (I) and of the chlorotriazine peak (II): the reduction of the group anthraquinone is faster and causes de dessorption of the dye; then, only the chlorotriazine group of the dye not adsorbed can be reduced, being controlled by diffusion; so, it has a much smaller increase with frequency than the peak of the anthraquinone group (of the adsorbed dye).

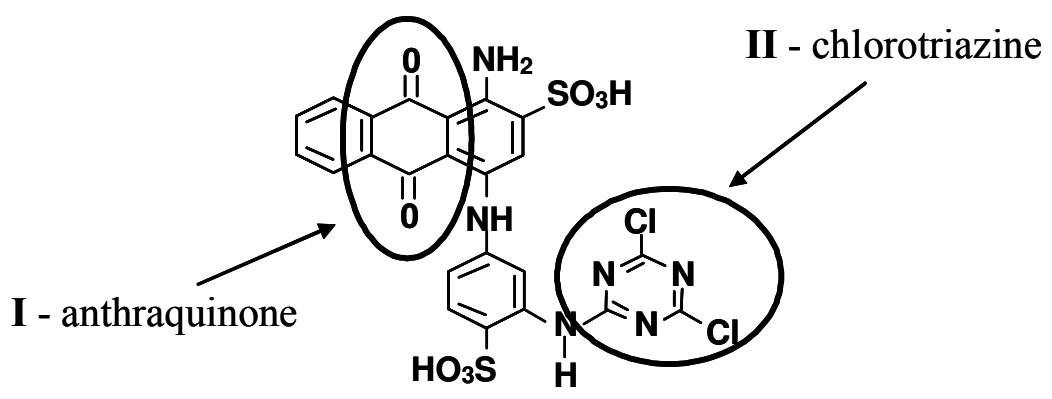

Figure 7. Anthraquinonic dye Procion Blue MX-R 


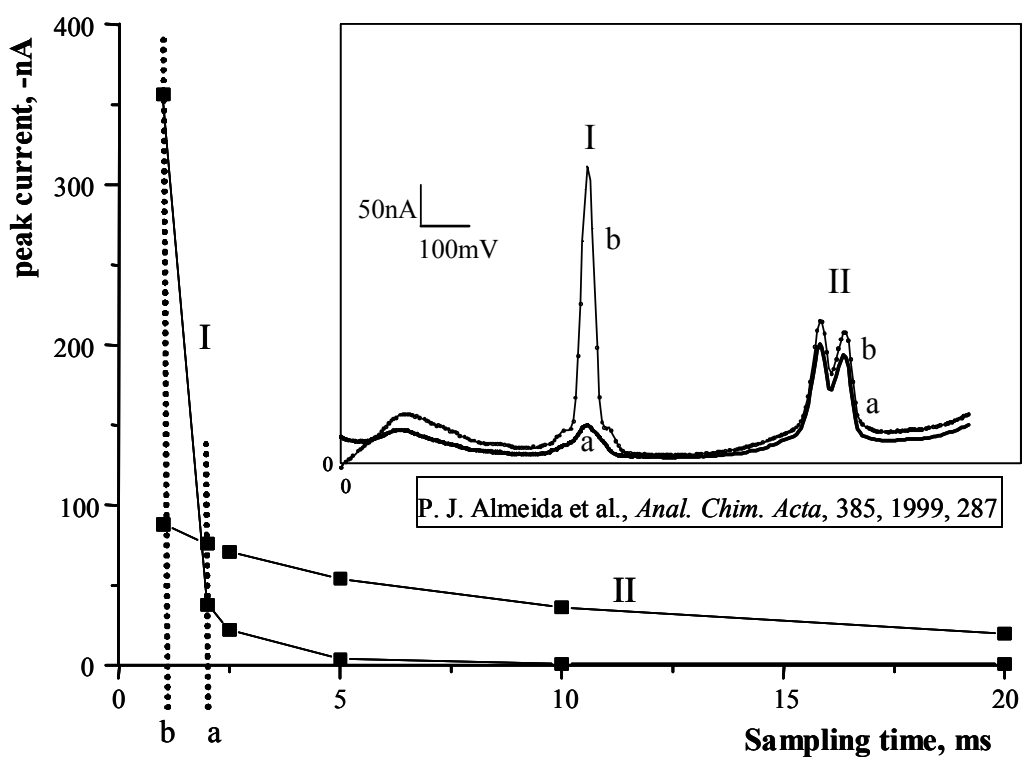

Figure 8. Voltammetric peaks obtained in the analysis of $5 \times 10^{-7} \mathrm{M}$ Procion Blue MX-R (acetate buffer) I - anthraquinone group; II -chlorotriazine group. Box: voltammograms obtained with sampling times of: a) $2 \mathrm{~ms}$; b-1 ms.

\section{Is it really necessary to always remove oxygen?}

A very well known problem that always impeded a wider application of the mercury electrode in voltammetry is the need for oxygen removal prior to the determination, despite several other characteristics of the mercury electrode that make it much more convenient that any solid electrode, especially in reduction processes. Moreover, this need for oxygen removal complicates the use of the electrode in flow detection, even with the introduction of some modifications to simplify and accelerate the desoxygenation process; for example, the mercury flow cell proposed by L. R. Taylor (Amer. Lab., 1993, 25, 44), which was not very successful.

Using a completely different strategy, this group was able, in certain situations, to eliminate instrumentally the interference of oxygen by a judicious choice of the current sampling time. This strategy is applicable to species that are reversibly reduced at the mercury electrode and that can be determined by adsorptive stripping voltammetry (it is worthy to note that these are characteristics of many organic species). In fact, using a square wave scan of potential and lowering the time elapsed between the application of the potential pulse and the sampling of the current (this can be obtained by increasing the square wave frequency) it is possible to obtain frequencies high enough to eliminate the interference of oxygen. This is explained because the square wave peak current of adsorbed species reversibly reduced has a much higher increase with frequency than the peak current of oxygen (limited adsorption and irreversible reduction). 
For instance, dimethylquinoxaline (DMQ) and hydroxyquinoxaline (HOQ) are two similar compounds that can be distinguished thanks to their different reversibility. As it can be seen in Fig. 9, at higher frequencies the voltammetric peaks are more apart and there is a much higher increase of the reversible peak.
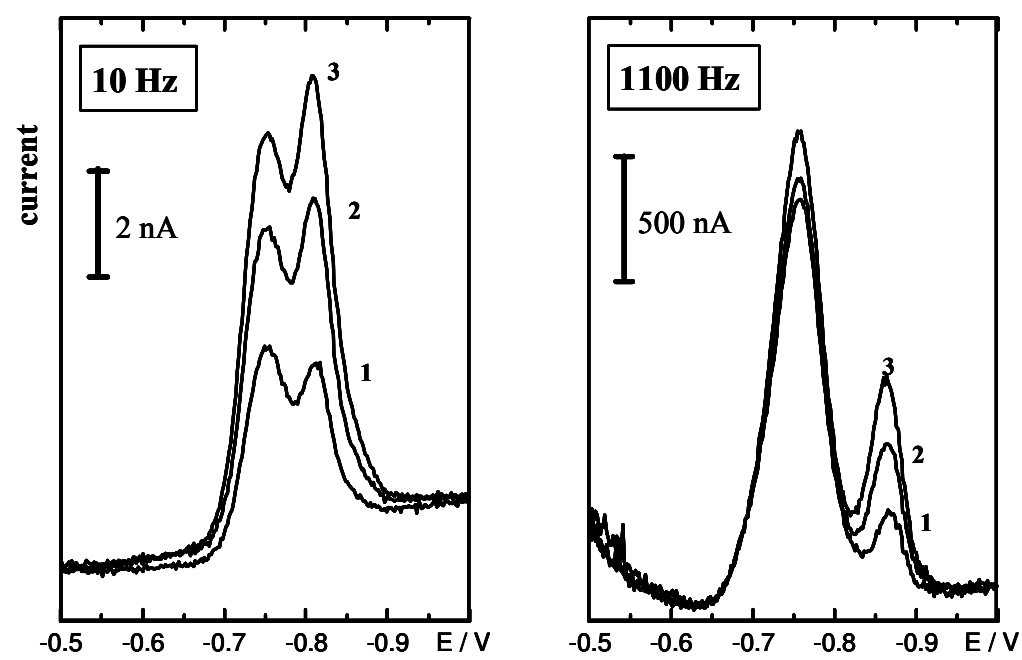

Figure 9. Voltammetric analysis of DMQ (reversible) and $\mathrm{HOQ}$ (irreversible): $1-5 \times 10^{-7} \mathrm{M}$ DMQ $+5 \times 10^{-7} \mathrm{M}$ HOQ; 2, $3-2$ additions of $5 \times 10^{-7}$ M HOQ. A. A. Barros et al., Anal. Chim. Acta, 385, 1999, 315

The possibility to determine DMQ in the presence of oxygen by increasing the square wave frequency can be explained in a similar way (Fig. 10).
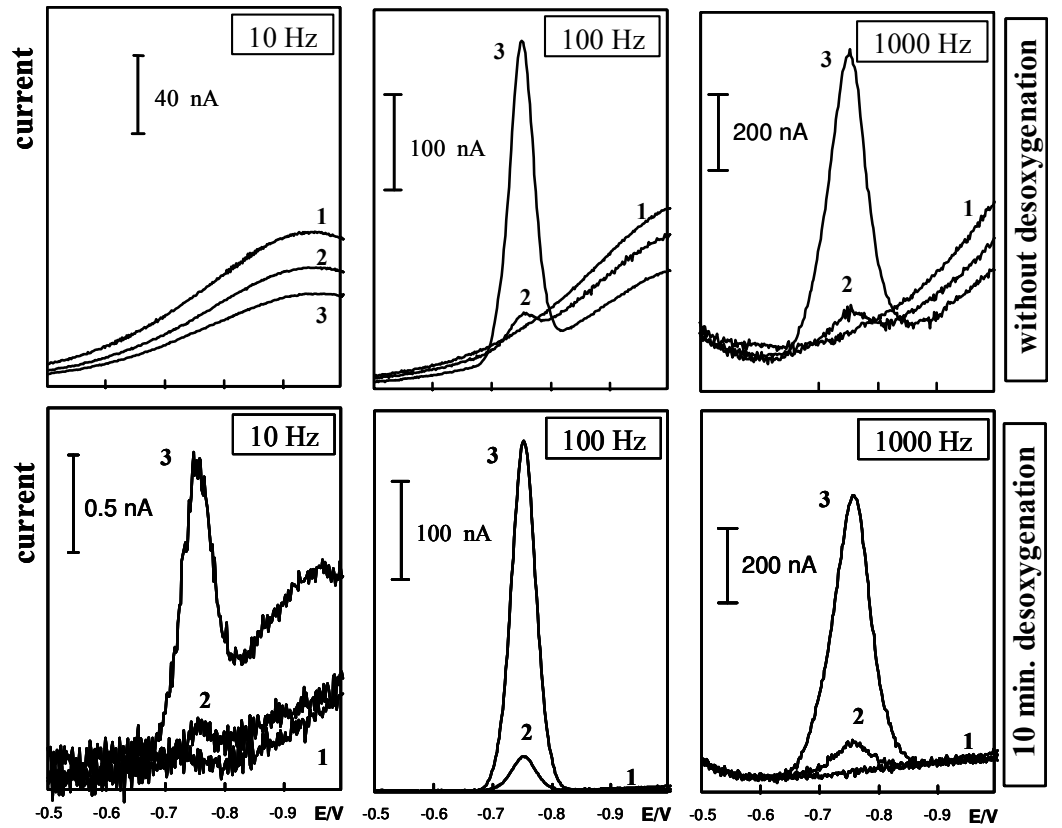

Figure 10. Effect of SW frequency and time of desoxygenation $\left(\mathrm{N}_{2}\right)$ in the determination of DMQ (derivatised diacetyl). [DMQ]: $1-0 ; 2-5 \times 10^{-8} \mathrm{M}$; $3-5 \times 10^{-7}$ M. A. A. Barros et al., Anal. Chim. Acta, 385, 1999, 315 
In fact, as the increase of the current with the increase of the SW frequency is much higher in the case of DMQ (reversible) than in the case of oxygen (irreversible), the latter becomes practically unnoticed for high frequencies.

As a first application of this result, it was possible to determine diacetyl (DMQ is diacetyl derivatised with orto-phenylenediamine) directly in an alcoholic drink (a brandy) without any need for oxygen removal, as it can be seen in Fig. 11: using a high frequency $(400 \mathrm{~Hz})$, voltammograms with and without oxygen removal are very similar.
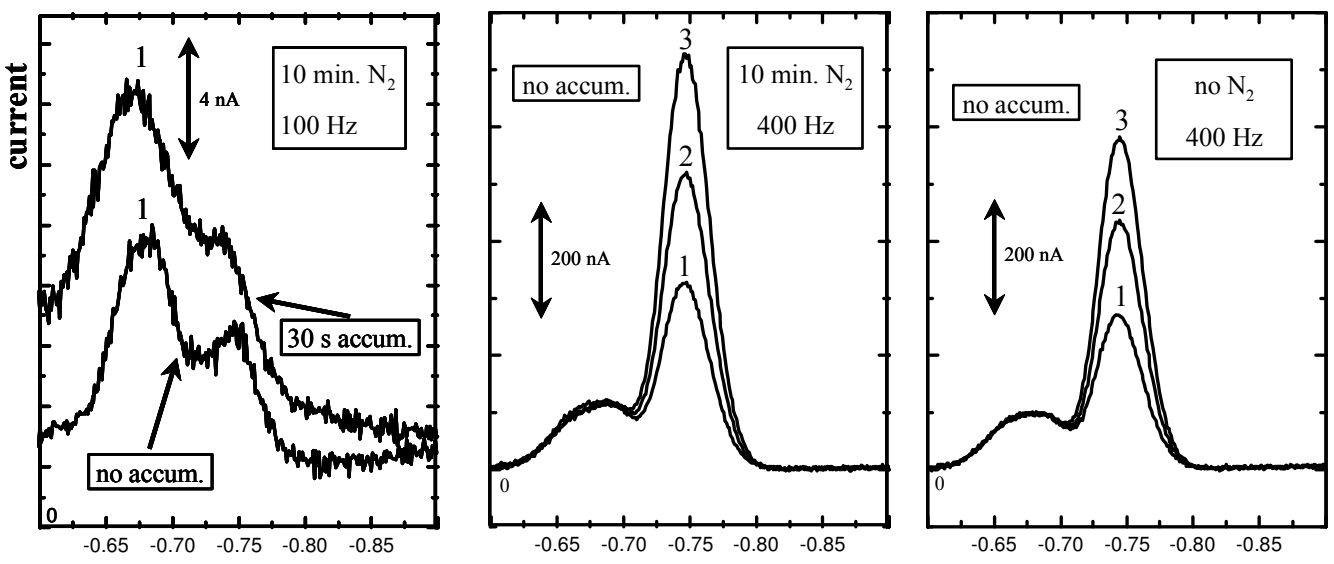

Figure 11. SW voltammetric analysis of diacetyl in a brandy. [DMQ] added: $1-0$;

$2-5 \times 10^{-7}$ M; $3-10 \times 10^{-7}$ M. A. A. Barros et al., Anal. Chim. Acta, 385, 1999, 315

Flow detection by adsorptive stripping voltammetry (2001/2002)

The next step, after being able to determine several species (including diacetyl) by adsorptive stripping voltammetry with no need for oxygen removal, was the investigation of the possibility of making the determination of those species in flow. As the problem of the desoxygenation elimination was solved, the main difficulty was now the adaptation of the hanging mercury drop electrode (HMDE) to be used as a flow detector.

\section{Construction of a HMDE voltammetric detector in flow (2001)}

The detector developed was based on the work of Taylor already mentioned (L. R. Taylor, Amer. Lab. 1993, 25, 44) and can be seen in Fig. 12. The mercury drop of the flow detector is placed inside a small cavity at the end of the tube where the analyte flows. That cavity was optimized in order to conciliate two opposing effects: it is large enough to reduce the flow rate of the liquid that strikes the mercury drop, avoiding its fall; it is small enough to avoid a large dilution effect, which would cause an inconvenient decrease in sensitivity. 

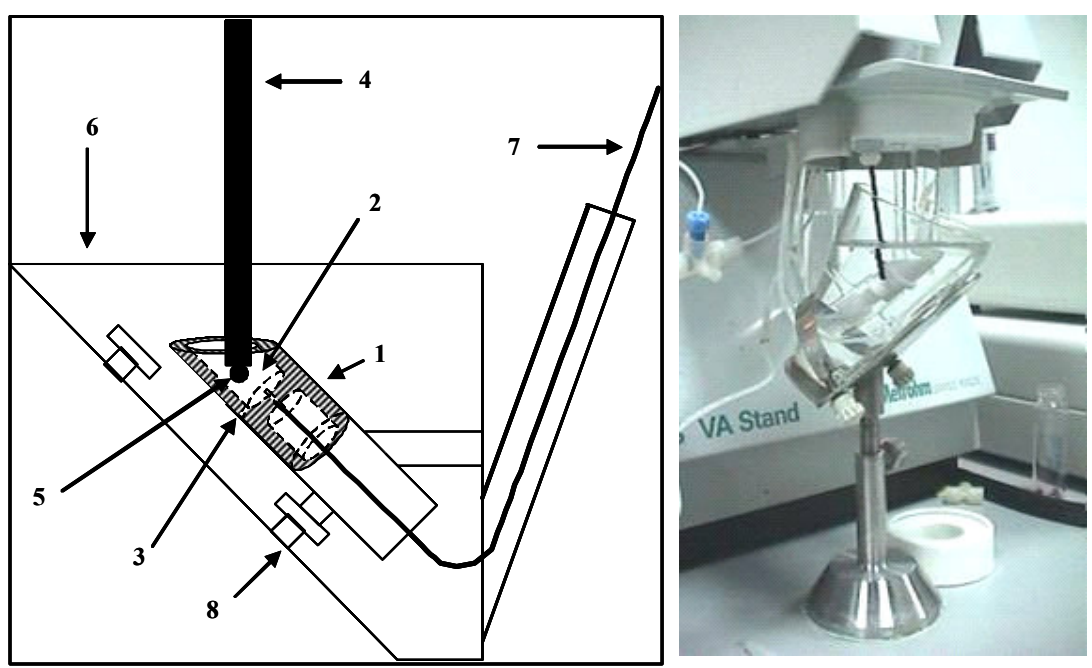

Figure 12. Flow cell containig a hanging mercury drop electrode (HMDE) detector. 1 - injector; 2 - internal cavity of the injector; 3 - hole for the discharge of mercury; 4 - capillar; 5 - mercury drop; 6 - glass container; 7 - flow tube; 8 flow tube support. Adapted from European Patent Application EP 1258725 A1, 2002

In Fig. 13 we can see the results obtained in the determination of diacetyl in "vinho verde" using adsorptive stripping voltammetry in flow and the method of standard additions. As it can be noticed, the determination of diacetyl is only possible after distillation of the wine, due to the interference of methylglioxal.

In the analysis of a port wine, by the contrary, the direct determination of diacetyl in flow was possible (Fig. 14), because this wine presented a much lower quantity of methylglioxal (probably because it was produced using a considerable amount of distillates).
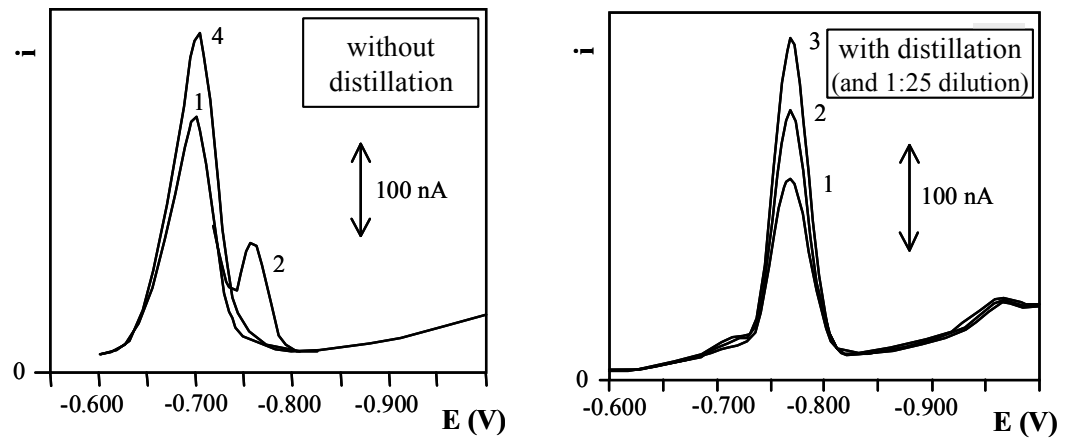

Figure 13. Analysis of "vinho verde" using adsorptive stripping voltammetry in flow. Standard additions: 1 - no addition; $2-1 \times 10^{-6} \mathrm{M}$ diacetyl; $3-2 \times 10^{-6} \mathrm{M}$ diacetyl; 4 $3 \times 10^{-6}$ M methylglyoxal. J. A. Rodrigues et al., Anal. Chim. Acta, 449, 2001, 119 


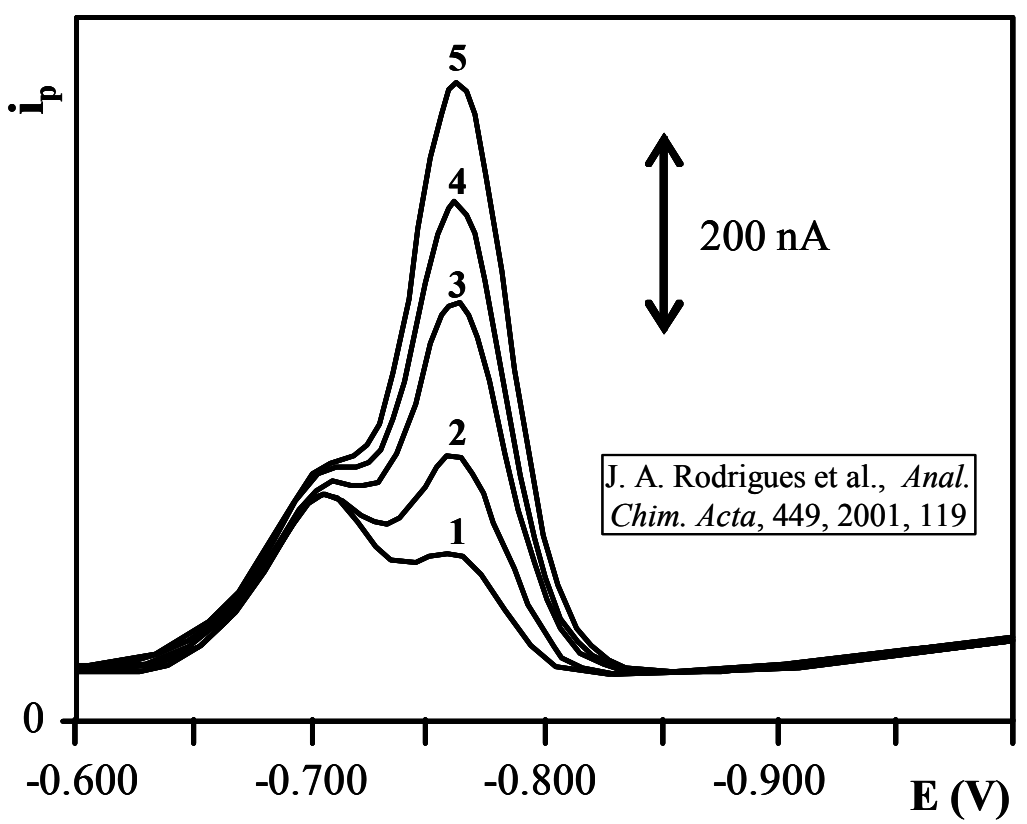

Figure 14. Direct determination of diacetyl in port wine (1: 25 dilution). Standard additions of diacetyl: $1-0 ; 2-4 \times 10^{-7} \mathrm{M} ; 3-8 \times 10^{-7} \mathrm{M} ; 4-$ $12 \times 10^{-7} \mathrm{M} ; 5-16 \times 10^{-7} \mathrm{M}$. (value obtained: [diacetyl] $=12.0 \pm 0.6 \mathrm{mg} . \mathrm{L}^{-1}$ )

\section{Automatic flow system for the determination of diacetyl in beer (2001-2002)}

As previously referred, the voltammetric determination of diacetyl in flow directly in wine was not possible due to the existence of interferences. In the case of beer the matrix is even more complicated, reason why it was decided to develop a pervaporation module in flow capable of extracting diacetyl from the beer matrix. Connecting this module with the voltammetric flow detector it was possible to project an equipment capable of determining diacetyl in flow directly in beer.

That project was patented in Portugal in 2003 (Patent $\mathrm{n}^{\mathrm{o}} 102$ 608) and the corresponding European Patent is under appreciation (EP 1258725 A1, 2003). The system (Fig. 15) works as follows: beer is pumped through the low chamber of a pervaporation module, where it is heated, with volatilization of diacetyl; the diacetyl vapour crosses the hydrophobic membrane (pervaporation membrane) which separates the lower chamber from the upper chamber and reacts with a solution of orto-phenylenediamine contained in this chamber to form dimethylquinoxaline; this is injected in an eluent and transported to the voltammetric detector in flow where it is determined. The system represented in Fig. 15 contains 2 pervaporation modules working in parallel and out of phase, with the objective of doubling the rate of the analysis. In fact, as the voltammetric detection is much faster ( 3 minutes, including washing) than the pervaporation step (10 minutes) it is possible to duplicate the frequency of the analysis using 2 pervaporation modules, without any changes in the voltammetric detection. 


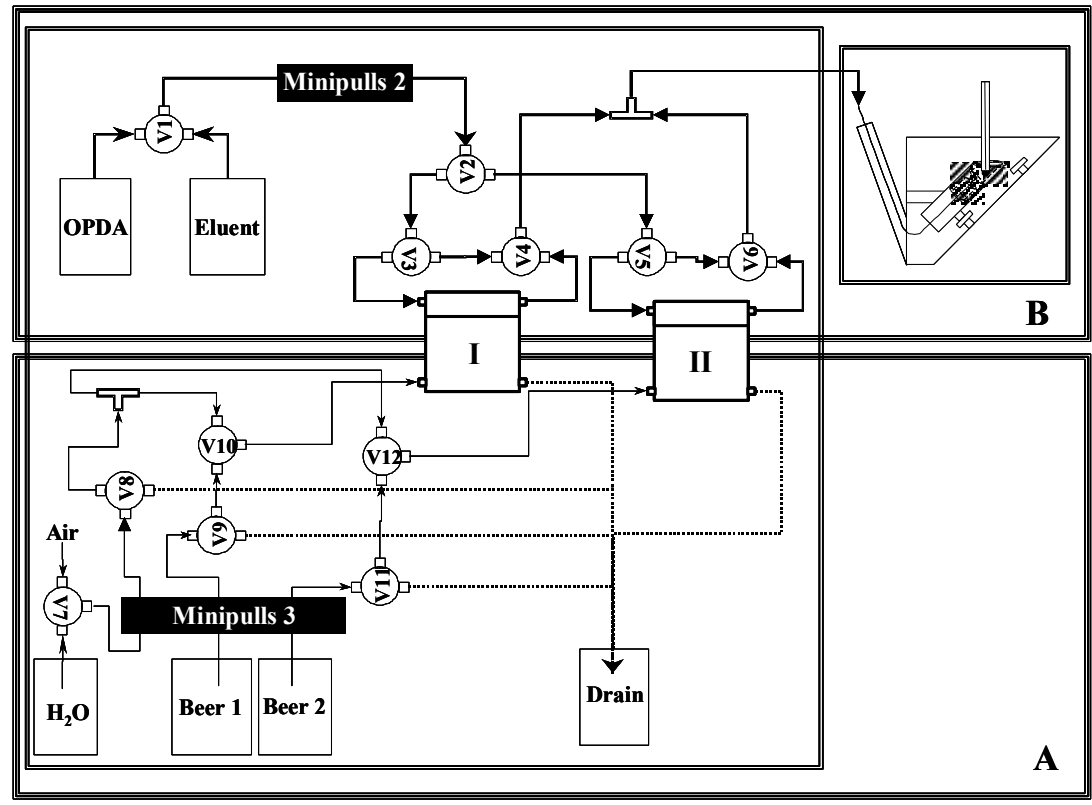

P. G. Rodrigues et al., Journ. Agric. Food Chem., 50, 2002, 3647

Figure 15. Automatic system for the flow voltammetric determination of diacetyl in beer. A - beer pervaporation; B - derivatization of diacetyl and detection. I, II - pervaporation modules, in parallel, working out of phase.

Fig. 16 presents the voltammograms obtained in the flow voltammetric determination of diacetyl in beer, using the method of standard additions.

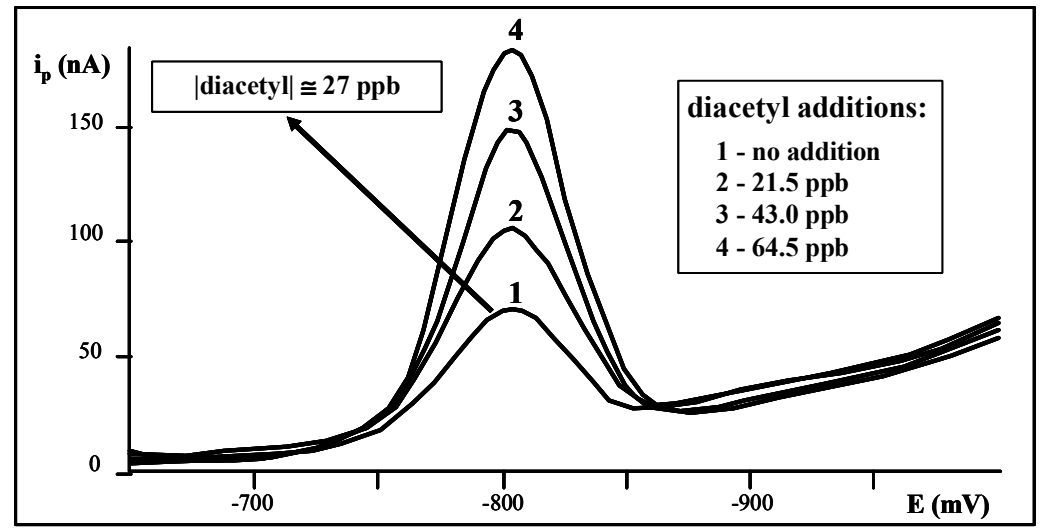

A. Barros et al., Proc. 28th Congress of the EBC, Budapest, Hungria, 2001

Figure 16. Voltammetric analysis of diacetyl in beer. Flow $=0.3 \mathrm{ml} / \mathrm{min}$.. Eluent: $\mathrm{pH} 7$ phosphate buffer $(0.1 \mathrm{M})$. [OPDA] $=0.05 \%$. Analysis time $=15 \mathrm{~min}$. (pervaporation $=10 \mathrm{~min}$.; detection and washing $=5 \mathrm{~min}$.).

The voltammetric method for the flow determination of diacetyl in beer was tested by comparing the results with those obtained using the official method of analysis (gas chromatography). As it can be seen in Table 2, the results obtained in the analysis of a large amount of samples of beer during the fermentation / maturation stage using both methods are practically coincident; nevertheless, the voltammetric method is simpler, faster, and requires less expensive equipment. 


\begin{tabular}{|c|c|c|c|c|c|c|c|c|c|c|c|}
\hline \multirow[t]{2}{*}{ set 1} & Volt & 0.04 & 0.02 & 0.07 & 0.07 & 0.03 & \multirow{2}{*}{ set 5} & Volt & \multicolumn{2}{|c|}{0.18} & 0.34 \\
\hline & Chrom & 0.04 & 0.02 & 0.05 & 0.05 & 0.03 & & \multicolumn{2}{|c|}{ Chrom } & & 0.36 \\
\hline \multirow[t]{2}{*}{ set 2} & Volt & 0.04 & 0.03 & 0.02 & 0.03 & 0.02 & 0.07 & 0.07 & 0.07 & & \\
\hline & Chrom & 0.04 & 0.02 & 0.02 & 0.02 & 0.02 & 0.06 & 0.06 & 0.06 & & \\
\hline \multirow[t]{2}{*}{ set 3} & Volt & 0.05 & 0.02 & 0.05 & 0.09 & 0.09 & 0.08 & 0.02 & 0.02 & 0.02 & \\
\hline & Chrom & 0.04 & 0.02 & 0.06 & 0.08 & 0.08 & 0.07 & 0.06 & 0.02 & 0.02 & \\
\hline \multirow[t]{2}{*}{4} & Volt & 0.04 & 0.06 & 0.09 & 0.10 & 0.07 & 0.07 & 0.06 & 0.05 & & \\
\hline & Chrom & 0.04 & 0.07 & 0.10 & 0.10 & 0.07 & 0.07 & 0.06 & 0.06 & & \\
\hline
\end{tabular}

Table 2. Determination of diacetyl (in ppm) during beer fermentation, using voltammetry (Volt) and chromatography (Chrom). Sets 1 to $4-$ end of maturation; set 5 - during fermentation (higher values).

A. A. Barros, XXVIII Encontro de Técnicos Cervejeiros, Madeira, 2001.

\section{Voltammetric method for the evaluation of beer ageing (2003)}

Beer ageing is one of the more important problems in beer industry. In fact, some time after production (between a few months and one year, depending on storage conditions) beer starts to develop some unpleasant flavours and tastes, becoming inappropriate to be consumed. The study of the problem is complex, because there are many compounds which can be responsible for these unpleasant effects. Anyway, it is generally accepted that the majority of the compounds is related with oxidation phenomena, reason why it is a general practice to add antioxidants to beer in order to reduce and retard the ageing. Sulphur dioxide is one of the more common antioxidants added; its concentration in the final beer varies between 10 and $20 \mathrm{ppm}$, and only a small part of it is formed naturally during the production of beer.

One of the more common forms of ageing is related with the release of certain aldehydes present in beer, initially "inactivated" by sulphur oxide in the form of adducts; ageing can be explained by the release of sulphur dioxide, with the consequent release of aldehydes. This connection of sulphur dioxide with beer ageing is depicted in Fig. 17. Although acetaldehyde is the main aldehyde present in beer (about $95 \%$ of the total), the organoleptic problems of ageing are not due to this aldehyde, because its perception threshold is quite high; on the contrary, $E$-2-nonenal, has a perception limit lower than $0.1 \mathrm{ppb}$, being one the compounds more often associated to the situations of beer ageing. 


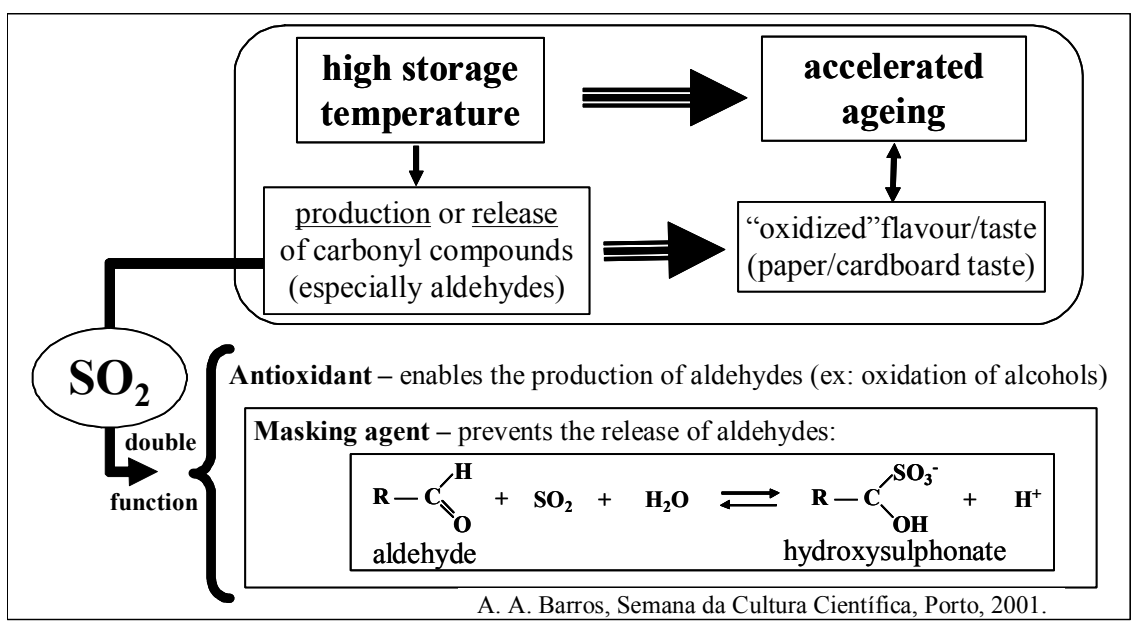

Figure 17. Sulphur dioxide a compound that can prevent the ageing of beer.

In beer practice ageing is exclusively based on the opinion of panels of tasters. This group of investigation decided to make a study trying to correlate the results of these panels of tasters with certain parameters which could be determined by voltammetry. Previously, it was shown that the ageing of beer could be explained by the release of certain aldehydes from their adducts with sulphur dioxide. This was exactly the aim of the study: if the concentrations of aldehydes and sulphur dioxide can both be measured, ageing would correspond to a decrease on sulphur dioxide concentration and an increase on aldehyde concentration. The research involved the voltammetric determination of sulphur dioxide and acetaldehyde (the main aldehyde present in beer) and the results obtained in beer distillates are in agreement with the expectations, as it can be seen in Fig. 18.

Following these preliminary results, it was decided to define an "ageing parameter", obtained by dividing the concentration of acetaldehyde by the concentration of sulphur dioxide; in fact, assuming that ageing causes a decrease in sulphur dioxide concentration and an increase in acetaldehyde concentration, beer ageing will have a double effect on the increase of this "ageing parameter". Using the same set of beers, it was found that there is a good correlation between the results obtained in this laboratory and those obtained by the normal panel of tasters, as it can be seen in Fig. 19. It is important to note that the classifications given by the beer tasters can vary between +1 and -3 and that beer must be rejected when the average panel score is less than -1.5 . 


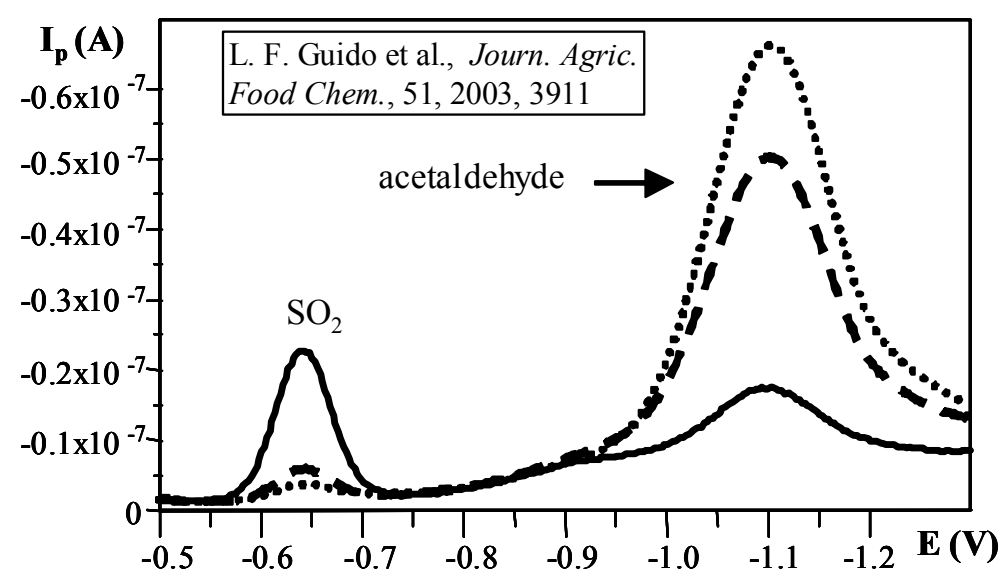

Figure 18. Voltammetric analysis of beer distillates: — fresh beer;

- - - forced ageing $\left(7\right.$ days, $\left.37^{\circ} \mathrm{C}\right)$; ..... natural ageing $\left(6\right.$ months, $\left.20^{\circ} \mathrm{C}\right)$.
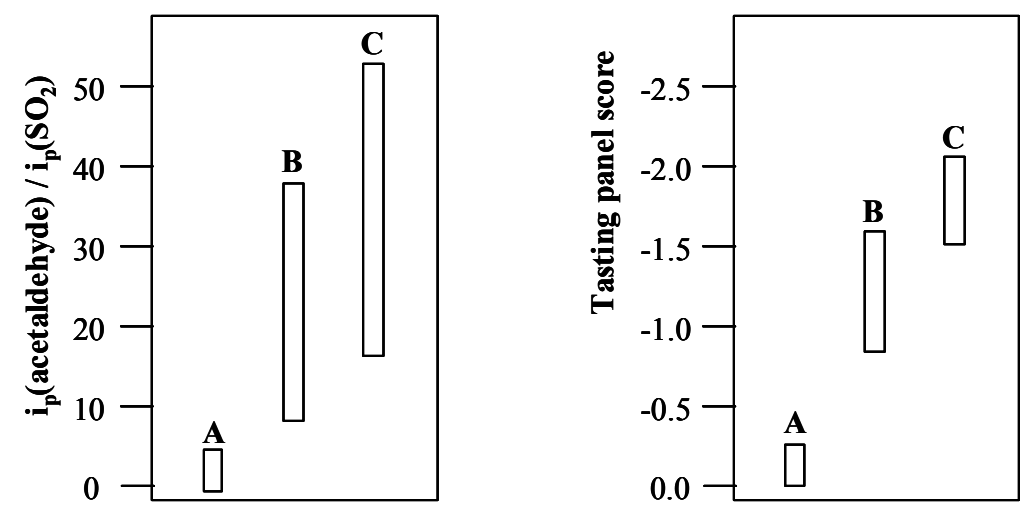

Figure 19. Analysis of 37 samples of beer. Correlation between the ratio of the voltammetric peaks (ip) of acetaldehyde and $\mathrm{SO}_{2}$ and the score of a beer tasting panel. A - fresh beer; B - forced ageing ( 7 days, $37^{\circ} \mathrm{C}$ ); $\mathrm{C}$ - natural ageing $(6$ months, $\left.20^{\circ} \mathrm{C}\right) . \quad$ L. F. Guido et al., Journ. Agric. Food Chem., 51, 2003, 3911

It is believed that this first trial to develop an instrumental way to study a problem that can only be assessed by the use of specialized panels of tasters is a first step to the finding of other instrumental ways, more objective, to evaluate the ageing of beer. This belief could explain why New Scientist and Chemistry in Britain decided to highlight the publication of the results (Fig. 20 and 21), although the method did not receive any enthusiasm of breweries, who knows fearing the disappearing of their panels of tasters at long term.

\section{New applications of the voltammetric system for analysis in flow (2004)}

Following the development of the HMDE voltammetric system for application in flow described previously, other possibilities for its use are being investigated. The first idea was the construction and commercialization of an equipment capable of determining diacetyl in beer. In this moment there is a 3 years project with this aim: Project Beervolt, involving our faculty and 2 beer companies and approved by the Portuguese Innovation Agency. The project started in April 2004 
and has as a final objective the production of an equipment to determine diacetyl which can be placed near the fermentation vessels. A photo of the prototype of the unity of control of this equipment can be seen in Fig. 22.

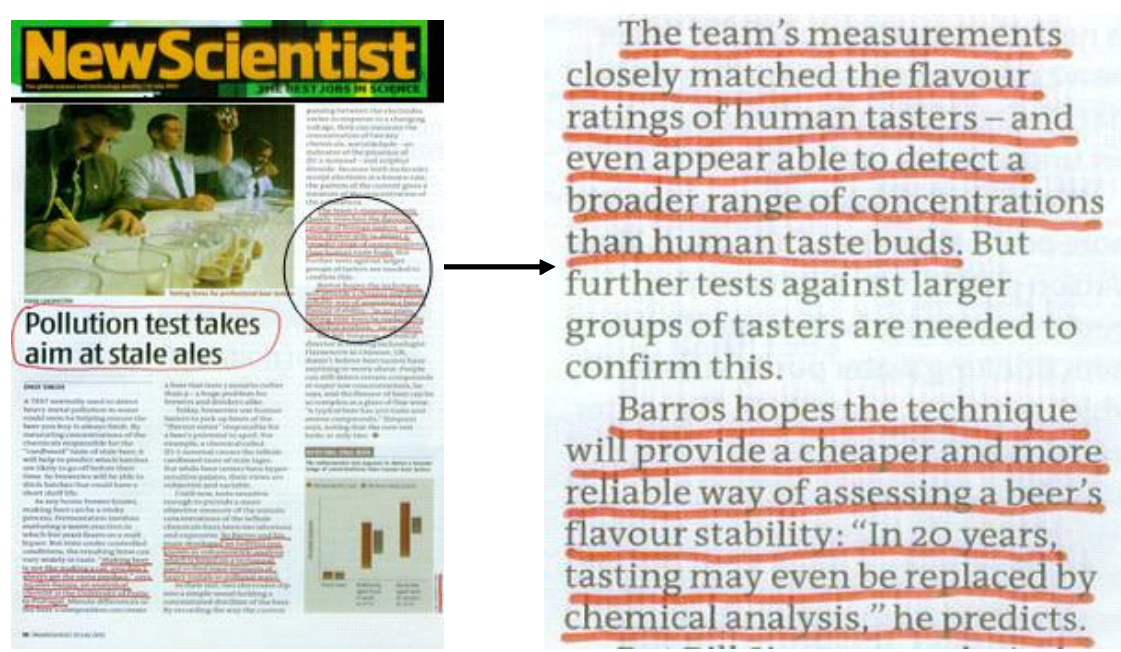

Figure 20. New Scientist, 2003 July 19, p. 18.
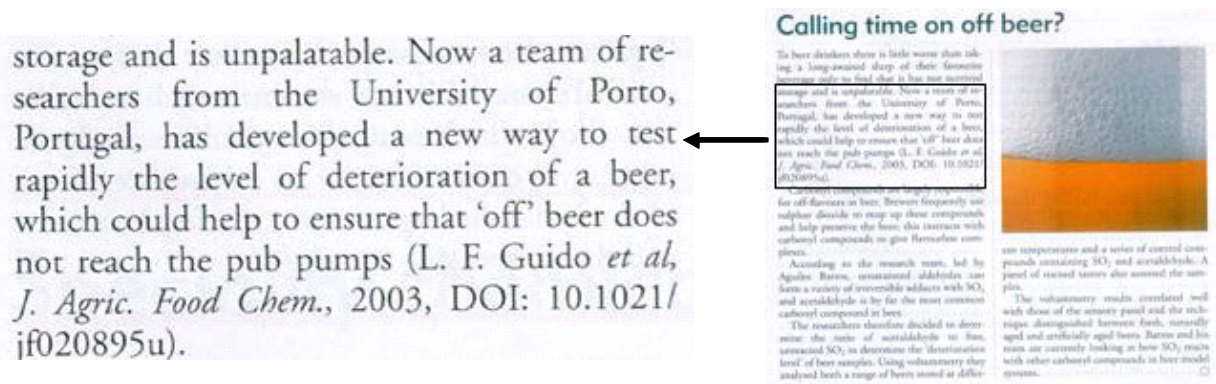

Figure 21. Chemistry in Britain July 2003, p. 8

In this moment the possibility of using the system Beerlab in the determination of other important beer compounds is being investigated, in order to try to make the equipment more appealing for brewers. One investigation, almost finished, is the determination of sulphur dioxide in beer, using a procedure similar to the used in the determination of diacetyl (Fig. 23).

Anyway, it is important to mention that there are two important differences: in the first place, beer has to be acidified before entering the pervaporation module, to facilitate the release of sulphur dioxide; second, there is no derivatization reaction in the upper chamber of the pervaporation module, but only an electrolyte solution to collect $\mathrm{SO}_{2}$.

Meanwhile, in a more academic perspective, the possibility of determination of other compounds using adsorptive voltammetry in flow is being investigated. An example is given in Fig. 24. 


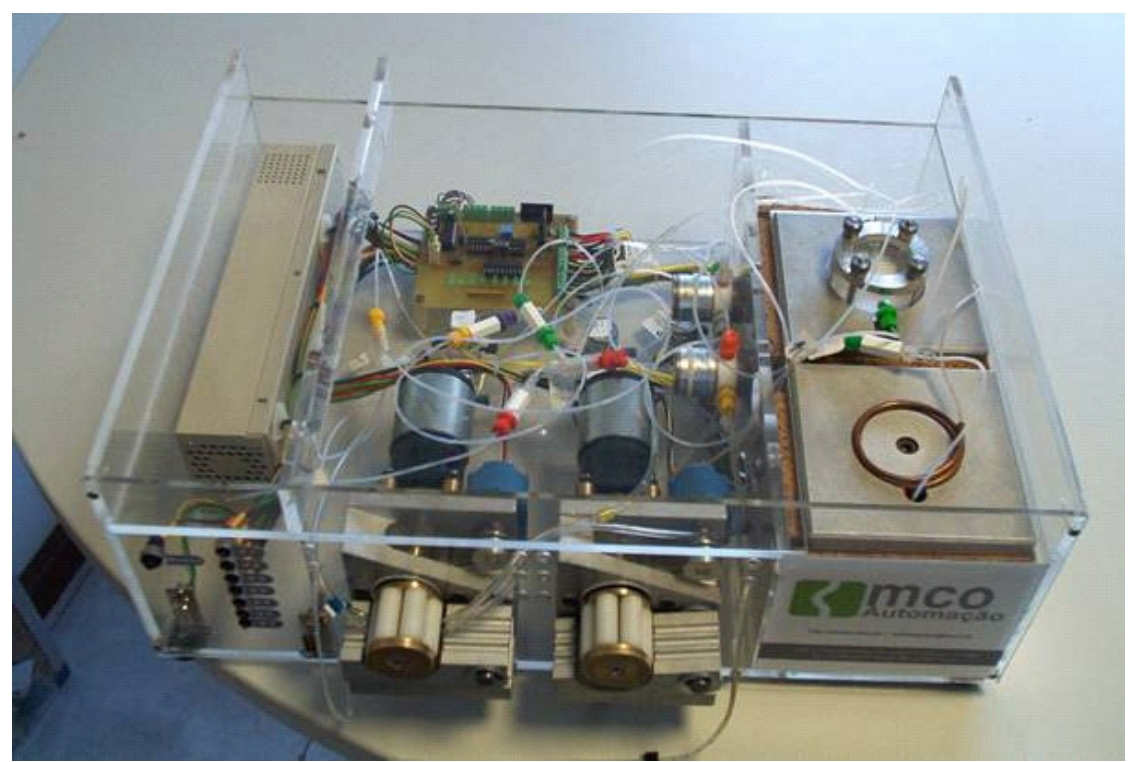

Figure 22. Photo of a prototype of Beerlab (version January 2005), the control unity of the equipment for the determination of diacetyl in beer which is being developed in the project Beervolt.

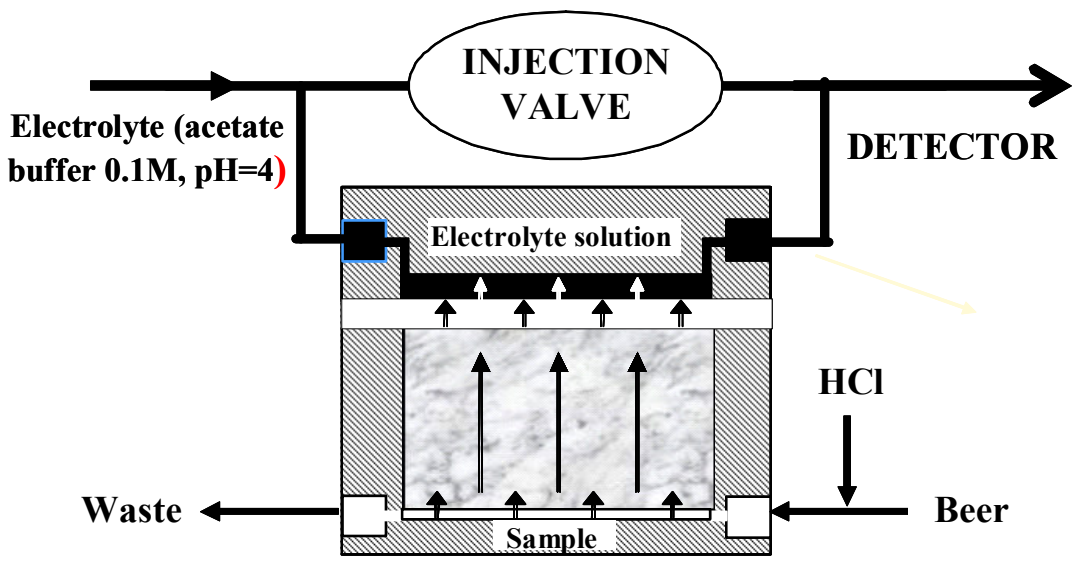

Figure 23. Voltammetric determination of sulphur dioxide in flow. Working diagram of the pervaporation module (adapted from J. A. Rodrigues, Keynote Lecture, XII Meeting of the Portuguese Electrochemical Society, Lisboa, 2003)

\section{Conclusion}

The investigation in voltammetry in which I was involved in the last 25 years was described. With this presentation I hope to have been able to prove the potentialities of a technique that has experienced a lot of difficulties in obtaining a wide acceptance.

Finally, I would like to say that after all these years my feeling is that it is very difficult to cross the line that separates investigation from useful applications and researchers almost always give up to leave their quiet model systems. It is not 
their entire fault, because careers are more and more based on number of scientific publications; the situation is even more difficult, because those that leave on the other side of the line tend to despise the usefulness of the academic research.

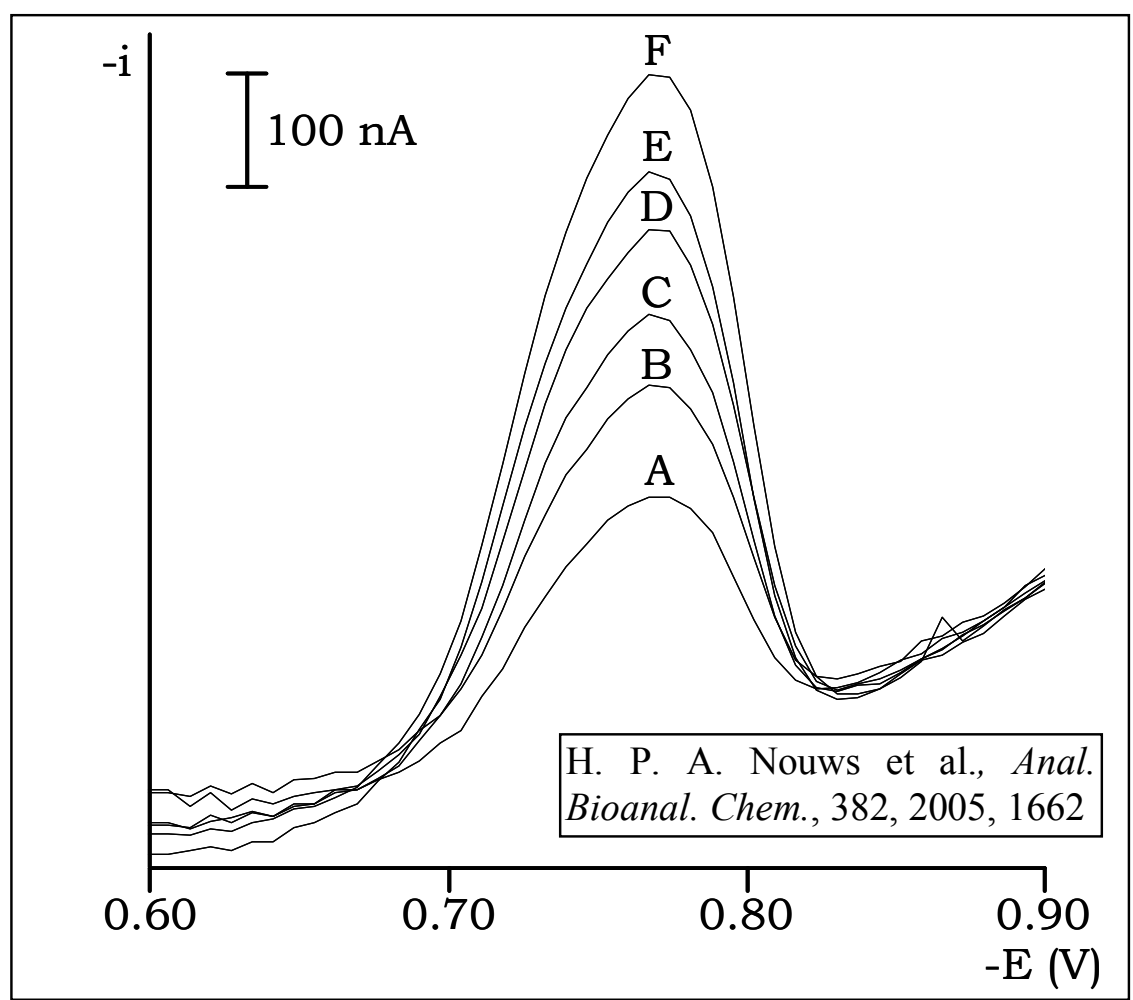

Figure 24. Flow determination of fluvoxamine (FVX) in a pharmaceutical preparation (Dumyrox). Standard additions of FVX (10-7 mol/L): A: 0; B: 2.00; C: 4.00; D: 6.00; E: 8.00 and F: 10.0.

\section{Acnowledgements}

I would like to thank all the people involved in this investigation. As they are too many, I will only refer those who obtained a Ph. D. degree in the group headed by Prof. Cabral: Maria Fernanda Cabral, Researcher at FCUP (retired); Maria Helena Barreira Lopes, Associated Professor at FCUP (retired); José António Maia Rodrigues, Auxiliary Professor at FCUP; Paulo Joaquim Ferreira de Almeida, Auxiliary Professor at FCUP; Luís Guilherme de Lima Ferreira Guido, Auxiliary Professor at FCUP; Pedro Miguel Gonçalves Rodrigues, Researcher at Unicer; Maria Adelaide Ferreira, Researcher at Instituto Geológico e Mineiro.

I finish as I started, dedicating this work to Professor João Cabral, who introduced me to voltammetry but also guided me in many other ways. In fact, Professor João Cabral was much more than a teacher and a researcher. The postcard sent by Dr. Arnold Fogg to the XIII Encontro da Sociedade Portuguesa de Electroquímica is a clear demonstration of the fact: 
"There is much that I could say about our successful collaboration from 1981, and about João and Fernanda's hospitality to both of us. Suffice it to say that we believe that João introduced us - partly through the Portuguese Electrochemical Society - to the 'real' Portugal, which we have come to love and enjoy very much in its diversity",

Arnold and Joyce Fogg

\section{References}

1. J. de Oliveira Cabral and H. A. Turner, "The polarography of azo dyes", J. Soc. Dyers Colour. 72 (1956) 158-167.

2. Arnold G. Fogg and Aquiles A. Barros and J.O. Cabral, "Differential-pulse Adsorptive Stripping Voltammetry of Food and Cosmetic Synthetic Colouring Matters and Their Determination and Partial Identification in Tablet Coatings and Cosmetics", Analyst 111 (1986) 831-835.

3. A.A. Barros et al., Electroanalysis 3 (1991) 243-245.

4. J.A. Rodrigues et al., J. Inst. Brewing 103 (1997) 311.

5. A.A. Barros et al., Anal. Chim. Acta 385 (1999) 315.

6. Zanoni et al., Anal. Chim. Acta 315 (1995) 41.

7. P.J. Almeida et al., Anal. Chim. Acta 385 (1999) 287.

8. L.R. Taylor, Amer. Lab. 25 (1993) 44).

9. European Patent Application EP 1258725 A1 (2002).

10. J.A. Rodrigues et al., Anal. Chim. Acta 449 (2001) 119.

11. Portuguese Patent No. 102608.

12. P.G. Rodrigues et al., J. Agric. Food Chem. 50 (2002) 3647.

13. A. Barros et al., Proc. $28^{\text {th }}$ Congress of the EBC, Budapest, Hungry (2001).

14. A.A. Barros, XXVIII Encontro de Técnicos Cervejeiros, Madeira (2001).

15. A.A. Barros, Semana da Cultura Científica, Porto (2001).

16. L.F. Guido et al., J. Agric. Food Chem. 51 (2003) 3911.

17. Pollution test takes aim at stable ales, New Scientist, 2003 July 19, p. 18.

18. Calling time on off beer?, Chemistry in Britain, 2003 July, p. 8.

19. J.A. Rodrigues, Neynote lecture, XII Meeting of the Portuguese Electrochemical Society, Lisboa (2003).

20. H.P.A. Nouws et al., Anal. Bioanal. Chem. 382 (2005) 1662. 